\title{
Research on the influence of internet consumer finance on the consumption behavior of rural residents in China
}

\author{
Meng Lei $^{1}$ \\ ${ }^{1}$ School of Finance, Harbin university of commerce, China
}

\begin{abstract}
Internet consumer finance is in the midst of the sustainable development of the current situation, this paper focuses on Internet consumer finance influence on rural residents' consumption in China, Through the analysis of selected data by SPSS software, the empirical study proves that the development of Internet consumer finance can promote the increase of rural residents' consumption expenditure. but the development of rural Internet consumer finance there are still some problems, thus put forward a series of countermeasures and Suggestions, for the relevant personnel to improve a certain reference and help.
\end{abstract}

\section{THE INTRODUCTION}

With the rapid rise of Internet economy, Internet consumer finance, as a new financial service model, has gradually become an important driving force to promote economic development. In recent years, the CPC Central Committee and the State Council have attached great importance to the reform and development of rural finance. The Ministry of Finance has continuously improved the policy support system, increased support and innovated policy tools to promote the benign development of rural finance and create a new situation of rural economic development. Stimulating rural demand is of great significance to stimulating domestic demand and promoting national economic growth. With the popularization of Internet technology in rural areas, the traditional consumption patterns and concepts of rural residents are gradually changing. E-commerce companies aim at the rural market and bring more availability and convenience to the consumption of rural residents. Under the background of the environment, in order to further study the Internet consumer finance pull function on the rural residents' consumption demand, and guide the Internet consumer finance better service in the rural economy, this article mainly through empirical analysis research of Internet consumption financial impact on rural residents' consumption behavior, and a series of conclusions and recommendations.

\section{Literature review}

From the definition of Internet consumer finance, Wang Xiaoqiang (2015) argue that the Internet consumer finance is a new type of financial services, is the combination of Internet technology and the traditional consumer finance new financial service mode, on the basis of using the Internet and information communication technology, to provide consumers in addition to the house of the goods or other than automobile consumption credit, And allow amortization of credit activities. From the perspective of the current situation and development trend of Internet consumer finance ${ }^{[1]}$.Zhang Chenfei (2020) believes that under the guidance of the development strategy of "Internet + " and with the continuous development of the Internet and information and communication technology in China, the scale of Internet consumer finance continues to expand and shows a trend of continuous explosive growth ${ }^{[2]}$. E Chunlin (2018) believes that Internet consumer finance is in a period of rapid development, with features and trends such as large traffic, diversified business operation modes and strong scenario-based mode. At the same time, various risks in the development process of Internet consumer finance are easy to be ignored and need to be constantly adjusted and improved in the development ${ }^{[3]}$.

In the research on the influence of consumer finance, Zhao Ranran (2014) elaborated the influence mechanism of consumer finance on the consumption behavior of urban residents. Through empirical test, it proved that the development of consumer finance is positively correlated with the consumption expenditure of urban residents ${ }^{[4]}$. Mao Erwan and Wei Xingyu (2020) found through empirical research that consumer credit plays a promoting role in China's economic development, and the effects of consumer credit on economic development in different regions are different ${ }^{[5]}$..Cui Lianxiang (2019) proved the promoting effect of Internet consumer finance on the economy through empirical analysis. However, due to the lack of relevant laws and regulations and imperfect regulatory measures, the financial risks of Internet consumer finance are relatively high ${ }^{[6]}$.

From what has been discussed above, the existing literature is mostly focused on the study of consumer finance, related literature on the basis of consumer finance discussed the current situation of the development of the Internet consumer finance, industry, 
etc., and related studies of Internet consumer finance, quantitative analysis of the article is less, which the Internet finance on rural residents' consumption behavior is less concerned. Therefore, this paper will focus on the research on the impact of Internet consumer finance on rural residents' consumption behavior, using multiple linear regression model to explore the impact of Internet consumer finance on the consumption level of rural residents, and make an empirical analysis.

\section{The current situation of Internet consumer finance and its influence channels on rural residents' consumption behavior}

\subsection{The current situation of Internet consumer finance and rural residents' consumption}

Internet consumer finance refers to providing individuals or families with consumption-related financial activities such as payment, savings, financial management, credit and risk management through the Internet. In recent years, its participants have expanded from the original $\mathrm{P} 2 \mathrm{P}$ dominated consumer finance market to the current online consumer finance based on e-commerce ecology. Secondly, the e-commerce market represented by online shopping continues to grow rapidly. Thirdly, Internet finance entered a real outbreak period in 2013, with breakthroughs in finance, investment and credit fields in 2014. According to iResearch, China's online consumer finance market is expected to reach 3.3 trillion yuan by 2019.

\subsection{The influence channels of Internet consumer finance on rural residents' consumption}

The influence channels of Internet consumer finance on rural residents' consumption are mainly divided into direct channels and indirect channels. From the point of view of direct channels, Internet consumer finance is characterized by convenience, directness, deep scene and strong penetration. It provides rural residents with a new fast and efficient consumption mode, which will promote consumption expenditure through direct consumption concept and improvement of consumption experience of rural residents. And secondly because of the Internet consumer convenience and availability to guide consumption is expected to greatly slows down the rural residents lack of temporary income caused by cautious motivation and restrain consumption, make the future cash flow of cash in advance, so as to realize the use of financial stimulus spending, consumption to promote economic, with the development of the economy to improve the benign cycle of financial development; From the perspective of indirect channels, the development of Internet consumer finance will also provide more employment opportunities for rural residents, thus promoting the increase of rural residents' income. At the same time, it will also broaden the consumption channels of rural residents and make their choices more diversified, thus stimulating the increase of rural residents' consumption.

\section{Empirical test of the impact of Internet consumer finance on rural residents' consumption}

\subsection{Data selection and source}

In this paper, the per capita consumption expenditure of rural residents was selected as the explained variable, and the data came from China Statistical Yearbook. Due to the lack of Internet consumer finance accurate statistical data, so the selection of rural residents per capita consumption credit balance as proxy variable of Internet development and change of consumer finance, explanatory variables is mainly rural residents per capita disposable income and per capita consumption credit balance, per capita disposable income of rural residents come from national statistical yearbook, Per capita consumption credit balance from the national economic and social development statistics bulletin.

\subsection{Model selection}

If there is relationship between independent variable and dependent variable, the change of the dependent variable is often influenced by several important factors, while multiple is a linear relationship between independent variable and dependent variable, conducted by the regression analysis is the multiple linear regression. This paper takes rural residents' per capita disposable income and per capita consumer credit as independent variables, and rural residents' per capita expenditure as dependent variables to conduct multiple linear regression analysis. The multiple regression model is as follows:

$$
y=\beta_{0}+\beta_{1} x_{1}+\beta_{2} x_{2}
$$

Where $X_{1}$ represents the per capita income level of rural residents, $\mathrm{X}_{2}$ represents the balance of per capita consumer credit of rural residents, represents the constant term, and Y represents the dependent variable per capita consumption expenditure of rural residents.

\subsection{Empirical test}

This article choose in $2001 \sim 2019$ rural per capita consumption expenditure, consumption per capita disposable income, per capita consumption credit balance data to set up the model, after using the SPSS data analysis to obtain the regression equation, through the test of goodness of fit and significance test to analyze and explain the explanatory variables can be explained the validity of the variables and the ability to explain is interpreted. The regression equation $y=80.208+0.762 x_{1}+0.283 x_{2}$ can be obtained through multiple linear regression model test (see Table 2).

\subsubsection{Goodness of fit test}

As can be seen from Table 1, the determination 
coefficient $\mathrm{R}^{2}=0.999$, and the adjusted determination coefficient $\mathrm{R}^{2}=0.999$, no matter it is $\mathrm{R}^{2}$ or the adjusted $\mathrm{R}^{2}$. Explanatory variables $X_{1}$ and $X_{2}$ can well explain the explained variable, the per capita consumption expenditure of rural residents, indicating that the regression model has a very good fitting degree to the observed sample values.

Table1.Model summary

\begin{tabular}{ccccc}
\hline Model & $\mathrm{R}$ & $\mathrm{R}$ & $\begin{array}{c}\text { R square } \\
\text { after } \\
\text { square } \\
\text { adjustment }\end{array}$ & $\begin{array}{c}\text { Error of } \\
\text { standard } \\
\text { estimation }\end{array}$ \\
\hline 1 & $.999 \mathrm{a}$ & 0.999 & 0.999 & 136.78146 \\
\hline
\end{tabular}

\subsubsection{Significance test}

First by the $\mathrm{T}$ test for the variables of the model test of significance, the Table 2 shows that the $\mathrm{T}$ test, all $\mathrm{P}$ values of partial regression coefficient is less than 0.05 , which has significant meaning, namely, when the confidence level of $95 \%$, the regression equation is credible, that is, the regression equation of believable degree was $95 \%$, the individual the explained variables meet the $\mathrm{T}$ test.

Table 2. Coefficient a

\begin{tabular}{cccccc}
\hline $\begin{array}{c}\text { Consta } \\
\text { nts }\end{array}$ & $\mathrm{B}$ & standard error $\begin{array}{c}\text { standardi } \\
\text { zation } \\
\text { coefficie } \\
\mathrm{nt}\end{array}$ & $\mathrm{t}$ & significance \\
\hline & 80.208 & 142.208 & & .564 & .581 \\
$\mathrm{X}_{1}$ & .042 & .060 & .762 & 10.642 & .000 \\
$\mathrm{X}_{2}$ & .087 & .026 & .238 & 3.326 & .004 \\
\hline
\end{tabular}

F test is a significance test for the model as a whole. As can be seen from Table 3, the observed value of $F$ in this paper is 6933.526 , and the $\mathrm{P}$ value is 0.000 , which has passed the $F$ test at the test level of 0.005 , that is, rural residents' per capita income and per capita credit balance have a significant joint impact on rural residents' expenditure, and the overall significance of the regression equation is high.

Table 3. Anova a

\begin{tabular}{|c|c|c|c|c|c|c|}
\hline Model & & $\begin{array}{l}\text { sum of } \\
\text { square }\end{array}$ & df & $\begin{array}{c}\text { mean } \\
\text { square }\end{array}$ & $\mathrm{F}$ & $\begin{array}{c}\text { significan } \\
\text { ce }\end{array}$ \\
\hline \multirow[t]{3}{*}{1} & $\begin{array}{l}\text { regressi } \\
\text { on }\end{array}$ & $\begin{array}{c}2594410 \\
09.4\end{array}$ & 2 & $\begin{array}{c}12972050 \\
4.7\end{array}$ & 6933.526 & $.000^{\mathrm{b}}$ \\
\hline & $\begin{array}{c}\text { Residua } \\
1\end{array}$ & $\begin{array}{c}299346.7 \\
05\end{array}$ & 16 & 18709.169 & & \\
\hline & total & $\begin{array}{c}2597403 \\
56.1\end{array}$ & 8 & & & \\
\hline
\end{tabular}

\subsection{Analysis of empirical results}

Through empirical analysis, explanatory variables $X_{1}$ and $\mathrm{X}_{2}$ can well explain explained variable $\mathrm{Y}$, that is, the consumption level of rural residents is affected by the per capita disposable income of rural residents and the balance of per capita consumer credit to a certain extent. The equation can be expressed as $y=80.208+$ $0.762 x_{1}+0.283 x_{2}$. Among rural residents' consumption credit balance as the proxy variable of Internet consumer finance development, from the perspective of mathematical statistics, the Internet consumer finance development has certain effects on the rural residents' consumption expenditure, which in the case of other levels, rural per capita consumption credit balances each increase of 100 yuan (Internet consumer finance each increase of 100 yuan), Rural consumer spending will increase by 28.3 yuan.

\section{Countermeasures and Suggestions}

\subsection{Strengthen the construction of the Internet consumer finance system and guide the innovative development of Internet consumer finance}

The empirical test shows that Internet consumer finance plays a promoting role in promoting the increase of rural residents' consumption expenditure, so it is necessary to strengthen the construction of Internet consumer finance. The government should introduce corresponding policies to support the development of Internet consumer finance: One is to strengthen the perfect network infrastructure, providing a complete basis for the development of the Internet consumer financial protection, 2 it is through preferential policies to attract electricity into rural areas, cultivate comprehensive Internet consumer finance market, 3 it is to attract talented people, to speed up the Internet consumer financial products innovation, so as to broaden the rural consumption market.

\subsection{Improve the social security system and increase rural residents' income}

We can see from the regression model, rural residents income of rural residents' consumption spending the influence coefficient of the highest, so play Internet consumer finance to promote economic, domestic demand is the premise of increasing the income of rural residents' consumption level, perfect the rural social security system, so as to release the rural residents consumption potential, stimulate the rural residents' consumption demand.

\subsection{Change the traditional consumption concept and improve the network cognitive ability}

Due to rural residents to urban residents are, use the Internet penetration rate lower, there are quite a part of the rural residents' cognition to the Internet still stays in terms of communication, entertainment function, therefore, first of all, the government should strengthen the propaganda and guidance of rural residents, change their perception of the Internet, so you can play the 
Internet consumer finance for the promotion of the rural residents' consumption, In addition, they should be guided to establish the consumption concept of moderate excessive consumption and accept the new consumption mode, so as to better play the role of Internet consumer finance in stimulating the economy and expanding domestic demand.

\subsection{Establish and improve relevant laws and regulations, and improve the supervision system of Internet consumer finance}

Due to the information asymmetry existing in Internet consumer finance, various small consumer finance companies have poor ability to resist risks and must prevent the crisis caused by various credit risks. Moreover, with the development of Internet technology, some criminals use network security loopholes to commit network fraud. Relevant departments must improve the relevant legal system to severely crack down on illegal acts such as network fraud or the sale of fake and shoddy goods in network consumption, so as to protect the legitimate rights and interests of rural consumers. Relevant departments should also strengthen the supervision of various Internet financial consumption platforms, improve market access standards, prevent bad enterprises from entering the market, ensure the sound development of Internet consumer finance industry, regulate the order of Internet economy, and then promote the optimization and development of rural residents' consumption economic structure.

\section{Conclusion}

In the Internet era, the Internet has gradually become a new engine to promote economic growth, injecting new impetus into consumer finance, and increasingly changing people's consumption mode and concept. This paper takes Internet consumer finance as the focal point, studies its influence on rural residents' consumption behavior, proves that the development of Internet consumer finance can promote rural residents' consumption expenditure through multiple linear regression model, and puts forward a series of countermeasures and suggestions for the development of Internet consumer finance in rural areas. With the continuous increase of rural residents' income and the continuous development and improvement of Internet consumer finance in rural areas, we believe that Internet consumer finance will make a great contribution to the development of rural economy.

\section{References:}

1. Huang Xiaoqiang. The Definition, Development Status and Suggestions of Internet Consumer Finance of Business Economics, 2019(08): 164-167.

2. Zhang Chenfei. Research on the Development Status of Internet Consumer Finance in China [J]. Science, Technology and Economy Guide, 2020,28(16):244.

3. E Chunlin. Internet Consumer Finance: Development Trends, Challenges and Countermeasures [J]. Southern Finance, 2018(03): 85-92.

4. Zhao Ranrun. Empirical Analysis of the Impact of Consumer Finance on Urban Residents' Consumer Behavior [J]. Northern Economic and Trade, 2014(11): 134-135.

5. Mao Erwan, Wei Yuxing. The influence of consumer credit on China's economic development and the heterogeneity of channel function [J]. Commercial Economics Research, 2020(18): 186-189.

6. Cui Lianxiang. Empirical Analysis of Consumer Finance Driving Economic Growth in the Internet Era [J]. Journal,2019(08): 164-167. 